\title{
Behavior Research, Indirect
}

National Cancer Institute

\section{Source}

National Cancer Institute. Behavior Research, Indirect. NCI Thesaurus. Code C15771.

Research concerning any factor or condition, exposure to which is theoretically susceptible to behavioral modification, but in which no actual behavioral work is being done (e.g., experimental studies on tobacco use, consumption of various dietary components, and exposure to many other environmental carcinogens). 